Teaching technology-mediated collaborative learning for trainee teachers

\author{
N. Sansone ${ }^{1}$, D. Cesareni ${ }^{1}$, I. Bortolotti ${ }^{1}$, S. Buglass ${ }^{2}$
}

1 Sapienza University of Rome, Italy

2 Nottingham Trent University, UK

MANUSCRIPT ACCEPTED IN TECHNOLOGY, PEDAGOGY AND EDUCATION. PRE-PUBLICATION VERSION; DO NOT CITE.

Corresponding Author: Nadia Sansone, Department of Social and Developmental Psychology, Sapienza University of Rome. Email: nadia.sansone @ uniroma1.it 


\section{Teaching technology-mediated collaborative learning for trainee teachers}

In a knowledge driven society, secondary education should let students develop appropriate and meaningful skills to live, think and work. To this aim, teachers require specific knowledge and competences about technology-mediated collaborative learning strategies while overcoming preconceptions and general sense of inadequacy towards these learning approaches. This exploratory study focuses on a learning path based on the "Trialogical" Learning Approach to consider the role of technology mediated collaborative learning in the educational development and classroom practices of trainee teachers. A multi-methods approach was used to analyse the collected data. Results indicate a good level of active participation in the activities leading to a general perception of effective learning. Participants report having acquired knowledge and skills, which will improve their professional practice. The positive value of introducing collaboration and technology in the learning path is highlighted.

Keywords: trainee teachers; technology-enhanced learning; collaborative learning; role taking; trialogical learning approach

\section{Introduction}

One of the main objectives of secondary education is to ensure that students acquire useful skills to achieve success not only in their studies but also in their future professional careers and life in general. These skills include ways of thinking (e.g., problem solving and metacognition), ways of working (e.g., communication and collaboration), tools for working (e.g., information literacy and ICT literacy), and living in the world (e.g., personal and social responsibility) (Binkley et al., 2012). Equipped with these skills, the citizens of tomorrow should be able to solve complex problems, deal with authentic activities, innovate knowledge work practices, create and support professional networks, build new technologies, and take responsibility for knowledge advancement in a globalized world. To this aim, socio-constructivism (Brown \& 
Campione, 1990; Lave \& Wenger, 1991; Vygotskji, 1978) claims for the teachers be aware of and embrace specific knowledge and competences regarding collaborative learning strategies and techniques that they could fruitfully use in their classrooms to promote students' active learning and the development of the above-mentioned competences.

In this paper, we therefore describe the exploratory research we have conducted on a learning path for trainee teachers based on the "Trialogical" Learning Approach (TLA: Paavola \& Hakkarainen, 2005). Specifically, the research considers the role of technology mediated collaborative learning in the educational development and classroom practices of trainee teachers. As we will later describe, in fact, TLA is a socio-constructivist model which emphasises the social dimension of learning and the need to organize activities aiming at using modern technologies to build useful knowledge objects.

\section{Background and theoretical framework}

The proper and meaningful use of technology in education is a relevant issue in modern society. Recent studies claim that the majority of teachers use technologies (e.g. IWB (Interactive White Board), personal computer, web tools and so on) to support traditional ways of teaching and learning, without exploiting their true potential (Harris, Mishra \& Koeheler, 2009; Lawless \& Pellegrino, 2007; Petrucco \& Grion, 2015; Sipilä, 2014). Why is this still happening?

A potential reason implicated is the training that teachers experience before undertaking their professional service. There is a general tendency to structure teacher training paths as courses in which the theoretical and methodological importance of such technologies is not actively linked to learning. Beginner teachers often learn about 
software or applications via 'how-to' lectures, gaining only passive examples of ways to use technology (Barton \& Haydn, 2006; Harris et al, ibidem; Tondeur, Roblin, van Braak, Voogt \& Prestridge, 2017). The trainees therefore, may not be able to fully understand or indeed gain experience of a number of important practice-based considerations, such as:

a) How, why and when to introduce technology, based on contingencies such as the discipline, the kind and number of students they will teach, and learning objectives;

b) The potential of technology to add value (e.g. allowing structured discussions which are easily traceable and evaluable) as well as its constraints (e.g. time and effort needed to plan and conduct technology-enhanced activities);

c) Ways in which technology can support their students' engagement and development of crucial societal competencies.

Moreover, the effect of passive and theoretical exposition to a digital tool is that trainees cannot prove themselves as able practitioners, so that they are left with a general sense of self-inefficacy when it comes to successfully incorporating technology in their teaching (Banas \& York, 2016).

Specifically, Ertmer and her colleagues (2006) found out that both extrinsic and intrinsic factors are relevant mediators in teachers' perceived ability to use technology in a significant way in their profession, with a prominence of intrinsic factors such as an individual's attitudes, belief system and confidence. Similar results have been reached in another study by Sadaf, Newby, \& Ertmer (2016) who investigated the connection between pre-service teachers' beliefs and attitudes, and their use of Web 2.0 tools in classrooms. Findings demonstrated that a positive attitude towards technology meaning essentially the belief of its usefulness - led to a more consistent introduction of these tools. 
Introducing technologies is not, of course, sufficient to positively influence educational practices alone and to shape the learning environment according to the socio-constructivist framework inspiring this study. As mentioned, the main pillar of this framework consists in conceiving learning as a meaningful participation to social practices in which students engage in productive interactions around specific learning goals (Lave \& Wenger, 1991; Vygotskji, 1978). To this aim, technology could be used as a tool to support the construction of a student's collaborative learning. Students, however, cannot just "learn" cooperation, unless they experience it directly. The possibilities of real collaborative learning reside in highly structured intra-group interactions which are strictly designated around well-defined scripts assigned to students and anchored to specific pedagogical models (Dillenbourg \& Hong, 2008; Author et al, 2009). A collaborative script consists of a series of instructions that prescribe how students should interact and collaborate. One of the most effective scripts used in teaching is Role Taking (RT; Strijbos, Martens, Jochems \& Broers 2007; Weinberger, 2008); this strategy includes students assuming a specific function that invokes duties and responsibilities during the individual and group activities. Indeed, collaborative work insists precisely on the commitment of participants that is expressed not only in taking responsibility for their own learning, but also for that of others (Author et al., 2016; Slavin, 2010; Wenger, Trayner \& De Laat, 2011).

In this paper, we describe a learning path for trainee teachers based on the "Trialogical" Learning Approach (TLA: Paavola \& Hakkarainen, 2005), that we consider as an effective and appropriate theoretical framework on which to anchor teachers' training considering its features (see below).

\subsection{The trialogical learning approach}

The TLA integrates "monological" (with emphasis on individual knowledge and 
conceptual processes) and "dialogical" (with emphasis on distributed cognition and the role of social and material interactions) learning approaches, with a third element: the intentional processes involved in collaboratively producing knowledge artifacts that are shared and useful for the community (Fig.1). The acquisition and participation metaphors of learning (Sfard, 1998) are, in this approach, embedded in the knowledge creation metaphor, which focus on both individual and social processes, conceptual knowledge and social practices, needed to foster collaborative creativity.

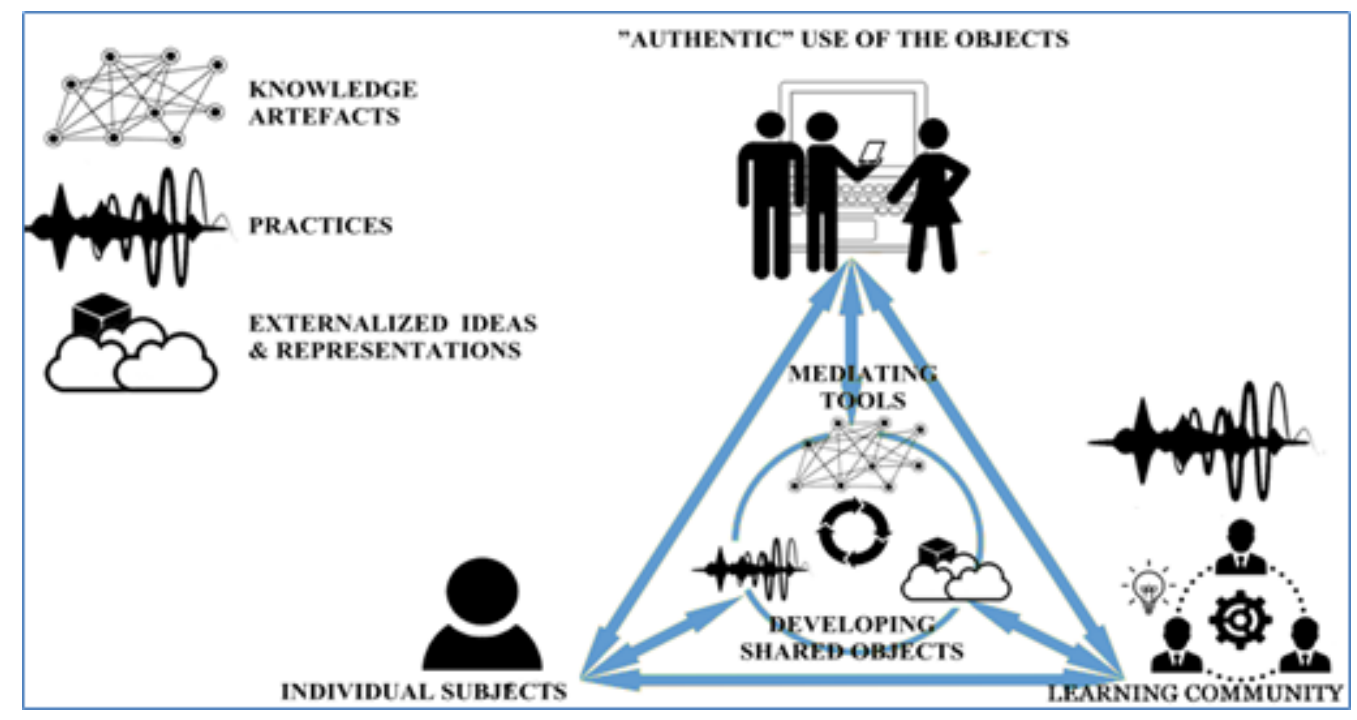

Figure 1. The Trialogical Learning Approach (Figure from Author et al., 2016)

The TLA focuses on the role of collaborative processes aimed to develop concrete knowledge artefacts and of new technologies, which could mediate and sustain these processes. Thus, it favours the use of environments, and tools that let individuals create, share, process, transform and organize objects of learning and in doing so, enable reflective transformation of knowledge practices.

The TLA is applied through six principles, the so-called design principles (Tab. 1: Hakkarainen \& Paavola, 2009; Paavola \& Hakkarainen, 2014), which guide the planning of technology-based teaching and learning activities to facilitate shared efforts 
of working with knowledge artefacts (Paavola, Lakkala, Muukkonen, Kosonen, \&

Karlgren 2011). In summary, these principles highlight the main characteristics of TLA:

mediation, knowledge artefacts, knowledge practices and object-oriented activities

(Paavola \& Hakkarainen, 2014).

Table 1. The six design principles of the TLA

TLA Design Principle Definition

DP1 Organizing activities around

Formative action must converge towards the shared "objects" realization of shared objects recognized as important and intended for actual use.

DP2 Supporting interaction between personal and social levels

DP3 Fostering long-term processes of knowledge advancement

DP4 Emphasizing development through transformation and reflection between various forms of knowledge and practices

DP5 Cross fertilization of various knowledge practices across communities and institutions

DP6 Providing flexible tool mediation
It is necessary to combine individual work with that of team, considering the different needs and "exploiting" inclinations and interests.

Learners should be provided with enough time for iterative inquiry cycles and supporting environments to let long-term processes take place.

New ideas and practices could emerge more easily when learning involves various forms of knowledge and practices: declarative, procedural as well as tacit.

Creating connections within other contexts promotes the acquisition of modes of interaction, ways of thinking and languages typical of contexts other than those of training.

The learning path should be supported by adequate and diversified technologies, suited to mediate collaborative activities and enhance aspects highlighted in the other design principles.

This article focuses on a TLA-based teacher-training learning path. Particularly, 
we wanted to let trainee teachers experience technology mediated collaborative learning so that they could challenge themselves in a new way of learning and teaching. In this way, we wanted teachers to recognise their personal limits - mostly internal - and abilities, to gain a more grounded opinion of technologies and a more informed understanding of how to effectively introduce them in classrooms to promote the development of 21 st century skills.

\section{Methodology and methods}

The aim of our research is to observe the effects of the teacher-training learning path here described on teachers' participation and perceptions of technologies as tools for teaching and learning. We wanted to explore whether the course was able to engage teachers, letting them experience first-hand technology enhanced collaborative learning and supporting an effective understanding of its potential.

Specifically, our research questions are:

1. To what extent did trainee teachers participate in the online discussions?

2. How did trainees evaluate the courses activities and their own learning?

3. Did the course promote a change in trainee teachers' opinions and attitudes towards collaborative learning and the use of technology in education?

\subsection{Participants}

Two-hundred and seventy-three teacher-trainees attended the course $(\mathrm{F}=197 ; \mathrm{M}=76)$. Most of them (about 55\%) were between the ages of 30 and 40 years old, 30\% were less than 30 and the other $15 \%$ were between 40 and 50 years old. Approximately $65 \%$ had prior teaching experience - though "precarious", as alternate teachers, lasting from 1 to 10 years. About $35 \%$ had no teaching experience at all.

Trainees were divided into three different classes according to their field of teaching: 87 
for sciences $(\mathrm{F}=51 ; \mathrm{M}=36) ; 138$ or humanities $(\mathrm{F}=104 ; \mathrm{M}=34)$; and 48 for languages and arts subjects $(\mathrm{F}=42 ; \mathrm{M}=6)$.

\subsection{Setting / Procedure}

The training path here described refers to the course 'Educational Technologies and Teaching' which the trainee teachers had to attend as part of their TFA (Tirocinio Formativo Attivo; translated as "Active Training Apprenticeship"), the mandatory training that prospective Italian teachers have to perform after their master's degree. TFA lasts one year and it is composed of several courses, offering a mix of theoretical and practical experience, aimed at promoting competencies and knowledge exploitable in their future profession.

The course in 'Educational Technologies and Teaching' was delivered in a blended form, comprising of a 4-hour face-to-face introductory lesson followed by 8weeks of online activities. "Blended", in our interpretation, does not involve only mixing face to face and computer supported interactions. Instead, an extensive vision of the blended approach is embraced, which proposes to blend different pedagogical methods, teaching strategies, individual study and group activities, and a large variety of tasks and end products. Compared to e-learning, the blended approach maintains the relevance of face to face meetings and activities as contexts within which the educational mission can be effectively delivered, and as able to empower computer based resources (Ligorio \& Sansone, 2009).

During the face-to-face lesson, the lecturer introduced theoretical content integrated with video examples on how to use technology in a school environment, in order to provide a common base on which to forge future course discussions. In addition, students had the opportunity to get used to the tools they were to use during the 8-weeks of online activities. Finally, the TLA approach and its six design principles 
were presented to students. At the end of the lesson, the trainee teachers received assignments and details about the subsequent online activities and their working-groups.

The online element was divided into three modules of approximately three weeks duration for each. In each module, participants were asked to analyse, discuss, and reflect on different topics connected to technology enhanced collaborative learning, with the final aim to collaboratively create a pertinent shared artifact at the end of the course: a pedagogical scenario including active and collaborative use of technologies, meant to be concretely applied in the classrooms they were following as part of their TFA.

Online, participants were distributed into separate discussion groups of approximately 10-12 members, which remained stable during the first two modules. Group discussions in these two modules were dedicated to: 1) identifying the pros and cons of the use of technology in schools and 2) gather and catalogue relevant experiences about the topic, be it from their own experiences or from scientific articles. During these two modules, group-work was supported by the assignation of specific roles:

- The Synthesizer who was in charge of writing weekly summary of his/her own group-discussion, identifying main issues and reporting them to the group;

- The Social Tutor tasked with promoting her/his own group-mates' participation;

- The Sceptic who was asked to stimulate discussion by emphasizing promising ideas and generating "prolific doubts" (Author et al., 2016). For the third module, the group composition changed, with trainees randomly grouped by teaching disciplines to engage in the final collaborative teaching activity. Each group 
received a pre-made template to guide them in writing a pedagogical scenario. The document included the following sections: context (level of education, $\mathrm{n}^{\circ}$ of involved students, areas of interest/disciplines, course duration, ICT tools), learning goals (contents, competences, ability), pedagogical design (activities, tasks, timing, evaluation), bibliography.

At the end of the course, as final step of the path, each trainee was asked to draw up an individual "report" and to answer a questionnaire. Both tools aimed at stimulating personal reflections and gathering useful research data (see par. 2.1.3). Since the course is TLA-based, in the following table (Tab.2) TLA design principles and their application in the course are presented.

Table 2. The six design principles in the course

TLA Design Principle Application

\begin{tabular}{|c|c|}
\hline $\begin{array}{l}\text { DPl Organizing } \\
\text { activities around } \\
\text { shared "objects" }\end{array}$ & - final artifact (the pedagogical scenario) \\
\hline $\begin{array}{l}\text { DP2 Supporting } \\
\text { interaction between } \\
\text { personal and social } \\
\text { levels }\end{array}$ & $\begin{array}{l}\text { - } \text { individual and small group-work } \\
\text { - } \text { role-taking } \\
\text { - from personal reading and web- } \\
\text { searching to group discussions }\end{array}$ \\
\hline $\begin{array}{l}\text { DP3 Fostering long- } \\
\text { term processes of } \\
\text { knowledge } \\
\text { advancement }\end{array}$ & 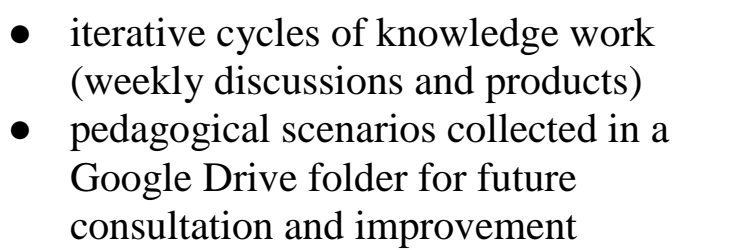 \\
\hline $\begin{array}{l}\text { DP4 Emphasizing } \\
\text { development through } \\
\text { transformation and } \\
\text { reflection between } \\
\text { various forms of } \\
\text { knowledge and } \\
\text { practices }\end{array}$ & $\begin{array}{l}\text { lecture, peer discussion, comparison } \\
\text { with theories, searching for and } \\
\text { evaluation of didactic experiences } \\
\text { from theoretical to practical knowledge } \\
\text { through the final scenario; from } \\
\text { practical back to theoretical through the } \\
\text { final report }\end{array}$ \\
\hline
\end{tabular}




\begin{tabular}{ll}
\hline & $\begin{array}{l}\text { critical reflection about the course } \\
\text { promoted through the final questionnaire } \\
\text { and the individual reports }\end{array}$ \\
$\begin{array}{l}\text { DP5 Cross fertilization } \\
\text { of various knowledge } \\
\text { practices across } \\
\begin{array}{l}\text { lommunities and } \\
\text { institutions }\end{array}\end{array}$ & $\begin{array}{l}\text { designing a pedagogical scenario as a } \\
\text { bridge between University, theoretical } \\
\text { approaches and school; } \\
\text { work-group and discussions with } \\
\text { colleagues of related and/or different } \\
\text { disciplines } \\
\text { notes/feedback by expert and professor }\end{array}$ \\
$\begin{array}{l}\text { DP6 Providing flexible } \\
\text { tool mediation }\end{array}$ & $\bullet \begin{array}{l}\text { MOODLE, Padlet, Google Drive, } \\
\text { specific domain-related software }\end{array}$ \\
\hline
\end{tabular}

\subsection{Data Analysis}

Considering the richness and complexity of the collected data, we developed a mixedmethods approach to analysis (Guba \& Lincoln, 1994; Niglas, 2000), which allowed us to observe the same phenomenon from different perspectives, thus gaining a broader understanding.

The first research question considered the trainees' participation in the webforum discussions. A quantitative investigation of 4578 notes compared trainees' discussions among disciplines, gender and covert role, both considering their number and length (sum of words for each). Differences were analysed through univariate ANOVA post- hoc tests.

The second and third research questions focused on the trainee teachers' opinions about the course, their learning acquisitions and their ideas about collaborative learning and technologies. To approach this analysis, we chose to integrate two different kinds of data: a final course questionnaire and an individual report. These activities were designed to complement each other with both promoting reflection. The anonymous questionnaire provided a structured response format being made up of three Likert-scales (1-5) and four open-ended questions about the trainees' overall 
appreciation of the course and the effectiveness of each activity for their learning achievements. It was auto-administered via Google modules and had a response rate of $26 \%$ (72 trainees). The online reports provided a narrative form of response, consisting of a document of three pages (maximum) in which the participants were asked to write down their reflections on the course following some general inputs about the overall learning path, as well as any personal achievement regarding the use of technology in education (skills, knowledge, attitudes). In addition, trainees were asked to answer the question: 'Which tools will you take from this course to add to your personal toolbox?' The narrative reports were mandatory and therefore rendered a $98.9 \%$ response rate (270 trainees).

Answers to Likert-scales questions were reported using summary descriptive statistics.

Open-ended questions from the questionnaire and individual narrative reports were analysed using content analysis based on the Grounded Theory approach (Glaser $\&$ Strauss, 1967). For each group of data - corresponding to the answers to specific questions or inputs - codebooks were defined, each consisting of a set of categories and subcategories.

\section{Results and discussion}

\subsection{How did trainees participate in the online discussions?}

As already stated, the online activities of the course were mainly based on webforum discussions about specific topics pertinent to the course (DP6: Providing flexible tools; DP3: Long-term processes of knowledge advancement) and about the collaborative construction of the pedagogical scenario (DP2: Supporting interaction between personal and social levels; DP1: Organizing activities around shared object). 
We have therefore considered indicators of active participation to be the number and length of the notes written down in the forum, with the length expressed in number of total words for each note.

The number of notes written by an individual trainee varied from 2 to 64, with an average of 16.73 (S.D. $=9.97)$. In terms of the discussion length, each student contributed to the forum discussions on the three modules with an average of 2070 words $($ S.D. $=1395.97)$. Individual notes on average were composed of 132 words. There was a degree of variability in the levels of participation across trainees, however, only a small number had low levels of active participation; indeed only 15 trainees (5.49\%) contributed less than 7 notes and less than 624 words (-1 S.D. in both the indicators); whereas, $75 \%$ of trainees wrote from 7 to 27 notes ( \pm 1 S.D. from average).

The following tables show the differences we traced in participation, with respect to disciplines, gender, and role. Starting with discipline (Tab. 3), we observed that science teachers wrote down more notes than trainees from other disciplines did, but their comments were shorter. Differences were statistically significant both for average notes number $(F(272)=5.49, p<.01)$ and notes length $(F(272)=3.47, p<.05)$.

Table 3. Participation according to disciplines

\begin{tabular}{|c|c|c|}
\hline Disciplines & $\begin{array}{l}\text { Average notes number } \\
M(S D)\end{array}$ & $\begin{array}{l}\text { Average notes length } \\
M(S D)\end{array}$ \\
\hline \multicolumn{3}{|l|}{ Human Sciences } \\
\hline$(N=138)$ & $15.29(8.19)$ & $137.90(69.98)$ \\
\hline Languages and Arts $(N=48)$ & $15.73(10.02)$ & $141.52(69.10)$ \\
\hline \multicolumn{3}{|l|}{ Sciences } \\
\hline$(N=87)$ & $19.67(11.91)$ & $116.91(51.11)$ \\
\hline Total $(N=273)$ & $16.73(9.97)$ & $132.02(65.11)$ \\
\hline
\end{tabular}

Considering trainee gender, female teachers $(\mathrm{N}=196)$ recorded more notes than their male colleagues ( $\mathrm{N}=77)$, but with no statistical significant difference (ANOVA), both 
for number and for length of notes (Tab. 4).

Table 4. Participation according to gender

\begin{tabular}{lll}
\hline Gender & $\begin{array}{l}\text { Average notes number } \\
\text { M(SD) }\end{array}$ & $\begin{array}{l}\text { Average notes length } \\
\boldsymbol{M}(\boldsymbol{S D})\end{array}$ \\
\hline $\boldsymbol{F}(\boldsymbol{N = 1 9 6 )}$ & $17.15(9.97)$ & $131.45(60.30)$ \\
$\boldsymbol{M}(\boldsymbol{N}=77)$ & $15.68(9.93)$ & $133.45(76.43)$ \\
Total $(\boldsymbol{N = 2 7 3 )}$ & $16.73(9.97)$ & $132.02(65.11)$ \\
\hline
\end{tabular}

Considering its potential in triggering active participation, we finally analysed the role effect on trainees' participation (Tab. 5) DP2: Interaction between personal and social level). In this case, we decided to consider just the first module in which the teacher assigned roles randomly. In the second and third module, as trainees volunteered for specific roles, it was judged that possible effects on participation would not be reliable. Students who autonomously requested a role, in fact, were probably more willing to participate actively, so their increased participation may not be due to role taking.

Table 5. Participation according to role

\begin{tabular}{lllll}
\hline Roles & $\begin{array}{l}\text { M }(\mathrm{SD}) \\
\text { average notes } \\
\text { module 1 }\end{array}$ & $\begin{array}{l}\text { M }(\mathrm{SD}) \\
\text { average notes } \\
\text { module 2 }\end{array}$ & $\begin{array}{l}\text { M }(\mathrm{SD}) \\
\text { average notes } \\
\text { module 3 }\end{array}$ & $\begin{array}{l}\text { M }(\mathrm{ds}) \\
\text { average notes } \\
\text { total course }\end{array}$ \\
\hline $\begin{array}{l}\text { Covering a role } \\
\text { in the I module }\end{array}$ & $8.43(4.87)$ & $5.72(4.39)$ & $6.53(5.64)$ & $20.45(11.26)$ \\
$\begin{array}{l}\text { Without role in } \\
\text { the I module }\end{array}$ & $5.35(3.78)$ & $5.05(3.68)$ & $5.76(4.66)$ & $15.38(9.1)$ \\
Total & $6.21(4.33)$ & $5.24(3.90)$ & $5.97(4.95)$ & $16.75(9.97)$ \\
\hline
\end{tabular}

Trainee teachers covering a role in the first module wrote down significantly more notes than students covering no role $(\mathrm{F}(263)=30.02, \mathrm{p}<.001)$ whereas their participation remains quite the same in the second and third module. Moreover, total number of notes written by students that took a role in the first period is significantly higher than that of 
students with no role in first period $(\mathrm{F}(272)=14.64, \mathrm{p}<.001)$. Role seems to be, then, a "triggering event" (Garrison, Anderson \& Archer, 2000) for trainees, able to promote active participation, as pointed out in the studies above mentioned (Strijbos, Martens, Jochems \& Broers, 2007; Weinberger, 2008).

Table 6. Participation indicators for specific roles

\begin{tabular}{|c|c|c|c|}
\hline Roles & $\begin{array}{l}M(S D) \\
\text { average notes in } \\
\text { module } 1\end{array}$ & $\begin{array}{l}M(S D) \\
\text { Number of words } \\
\text { written in module } 1\end{array}$ & $\begin{array}{l}M(S D) \\
\text { Average notes } \\
\text { length in module } 1\end{array}$ \\
\hline Skeptic $(N=25)$ & $7.68(4.62)$ & $820.16(384.99)$ & $131.37(79.73)$ \\
\hline Synthesizer $(N=24)$ & $8.00(4.81)$ & $1345.67(741.17)$ & $189.07(86.02)$ \\
\hline Social tutor $(N=25)$ & $9.60(5.13)$ & $1057.84(672.68)$ & $121.31(52.59)$ \\
\hline No role $(N=190)$ & $5.35(3.78)$ & $785.45(656.98)$ & $159.22(92.37)$ \\
\hline Total $(N=264)$ & $6.21(4.33)$ & $865.56(665.14)$ & $155.71(88.83)$ \\
\hline
\end{tabular}

With respect to each specific role, we applied a post-hoc variance analysis (ANOVA) (Tab. 6) ${ }^{1}$ Participation in the module 1 was significantly different according to the role, both in terms of number of notes $(\mathrm{F}(3)=11.10, p<.001)$, total number of words published during the course $(\mathrm{F}(3)=7.63, p<.001)$ and the notes length average $(\mathrm{F}(3)=$ $3.56, p=.015)$. In particular, the difference in the number of notes is statistically significant between trainees without a role and trainees covering roles, but with no difference emerging within roles.

There are, instead, differences in the number of words written by trainees with different roles. We believe that this difference may be related to the nature of the 
scripted roles (Author et al., 2016; Dillenbourg, 2008): the synthesizer was expected to summarise his/her colleagues' interventions to allow further discussion (Scardamalia \& Bereiter, 2006) (DP3: Long-term processes of knowledge advancement), therefore, he/she would post long comments and actively participate. The social tutor took the responsibility of sustaining participation of all the members of the group (DP2: Interaction between personal and social level), and to this aim wrote down many frequent notes to solicit participation (Author et al., 2016), sometimes with brief interventions, aimed mainly at gaining the attention of the group.

\subsection{How did trainees perceive and evaluate the activities of the courses and their own learning?}

\subsubsection{Appreciation of the course and of the activities}

Considering the 72 questionnaires (26\%), the overall evaluation of the course obtained an average score of 3.71 points out of 5 . A total of $65 \%$ of students reported being satisfied or very satisfied with the course (scores 4 and 5), while $10 \%$ showed it total or partial dissatisfaction (scores 1 and 2). The activity that was most appreciated by the majority of participants (Tab. 7) was the final collaborative creation of educational project $(\mathrm{M}=4.35)$ (DP1: Organizing the activities around shared objects).

Table 7. Appreciation of the various activities of the course (p. 1 to 5)

\begin{tabular}{lccc}
\hline Discipline & $\begin{array}{l}\text { Discussion on } \\
\text { Technologies }\end{array}$ & $\begin{array}{l}\text { Searching learning } \\
\text { experiences }\end{array}$ & $\begin{array}{l}\text { Writing the } \\
\text { project }\end{array}$ \\
\hline Human Sciences & 3.48 & 3.56 & 4.52 \\
Languages and Arts & 3.33 & 4.05 & 4.71 \\
Sciences & 3.21 & 3.25 & 3.83 \\
Total & 3.35 & 3.60 & 4.35 \\
\hline
\end{tabular}

Through the content analysis of the 270 individual project reports, however, we identified four specific aspects that the trainee teachers considered positive about the learning path followed. Most appreciated the possibility to compare different points of 
view (73\%) and to work concretely in groups (58\%) (DP2: Interaction betweenpersonal and social levels). Furthermore, $32 \%$ of trainees were positive about being given the opportunity to re-evaluate technology enhanced learning and to reflect while planning the pedagogical scenario (26\%) (DP4: Transformation and reflection between knowledge and practices): "The strength in having used technology has been just that: we have collaborated, we have compared our opinions, both on the platform and exchanging ideas on Whatsapp, and finally we have built something concrete. Everyone has been able to put their own specific potential to serve the group" (Ant, M, Sciences).

Exploring the activities in more detail, the analysis of the related open-ended question (on the end of course questionnaire) allowed us to consider specific aspects, such as role taking. In particular, with respect to the role of social tutor $76 \%$ of trainees covering the role claimed that it had a positive effect on their participation in the activity (DP2: Interaction between individual and social level), confirming the importance of scripts to solicit participation in collaborative learning contexts (Dillenbourg \& Hong, 2008). Trainees reported that the role stimulated more active and proactive participation (50\%), and improved their organizational and metacognitive skills (46\%) (DP4: Transformation and reflection between knowledge and practices). The sceptic role too was perceived as having a positive impact on participation (75\%), with trainees reporting that it empowered their personal skills - meta-cognitive, organizational and reflexive (34\%) (DP4: Transformation and reflection between knowledge and practices). Others appreciated its capability to facilitate the construction of knowledge in the group process (32\%) ((DP3: Long-processes of knowledge advancement). For both the social tutor and sceptic roles, $25 \%$ of trainees reported no perception of increased participation from undertaking the role. For the role of synthesiser, $90 \%$ of trainees who assumed the role of believed that it had a positive 
effect on their participation, with it reinforcing their reflective skills (50\%), motivating their participation (10\%), and helping them to understand the practicality of the work that was taking place (30\%).

An interesting finding from the questionnaire, showed that some of the students who had been assigned a role (14\%), while positively judging the activity, had in fact perceived the role given them as negative due to the restrictions enforced by the role descriptors. These trainees reported that they would have preferred more freedom in choosing what role to cover and how.

\subsubsection{Personal learning following the course}

In response to the open-ended question "What skills you feel you have developed or strengthened?" the trainees offered a number of different answers that we have categorized (Tab. 8) into 7 categories $(\mathrm{N}=94)$.

Table 8. Skills perceived as having been promoted by the course

\begin{tabular}{lcc}
\hline Skills & N. & $\%$ \\
\hline Collaborative learning & 38 & 52.8 \\
Technology enhanced learning & 34 & 47.2 \\
Metacognition and creativity & 11 & 15.3 \\
Teaching & 5 & 6.9 \\
None & 3 & 4.2 \\
Communication and team-working & 2 & 2.8 \\
Self-efficacy & 1 & 1.4 \\
Total & 94 &
\end{tabular}

The trainees believed that participation in the course had allowed them to strengthen or 
develop knowledge and skills relating to collaborative learning (53\%), "I have now a better understanding of the effectiveness (and problems) of the group work"; "I developed the knowledge related to collaborative learning. I hope, in the future, to offer it to my students "; "I am more willing and able to work in groups." (DP2: Interaction between personal and social levels). Another milestone reached according to many of the trainees was to have honed their knowledge and skills with respect to the use of technology in education (47\%) (DP6: Providing flexible tools):

"Definitely I've earned a greater awareness of the role of the teacher with respect to technology. Digital competence is undoubtedly strengthened. I first met the great application Google Drive! Surely I have gained more knowledge about the use of technologies in schools, the tools, their applications and contexts in which they are used; this thanks to the exchanges with colleagues." (Cla, F, Language)

Similar findings were apparent during the analysis of the 270 reports. When asked to specify which elements they would take from the course to their toolbox for future use as teachers, some $55 \%$ focused on the opportunity they had to learn how to use digital technologies (applications, software, learning environments) which they did not know existed prior to the course. Trainees claimed to have "learnt by doing" how to work in groups $(46 \%)$ and how to transfer it in their profession within a general theoretical framework of constructivism (37\%), promoting the construction of knowledge, in addition to collaborative learning: "The other discovery in which I did not imagine coming across during a course on the use of technology concerns the cooperative approach. In fact, I had never put in relation these two aspects: I found that if done as a group, things like internet searching or PPT making are much more productive and technologies allow to collectivize efforts and results” (Mar, M, Humanics). 
Altogether these findings confirm the effectiveness of the course in sustaining the development of those knowledges and competencies conceived as crucial (Binkley et al., 2012; Brown \& Campione, 1990; Lave \& Wenger, 1991; Vygotskji, 1978).

\subsection{Did the course promote a change in participants' opinions and attitudes towards collaborative learning and the use of technology in education?}

\subsubsection{Change in participants' opinions and attitudes towards collaborative learning Collaborative Learning}

Almost half of the trainees (44\%) responding to the questionnaire affirmed that the course had promoted the acquisition of useful knowledge and skills ("I now understand that working in groups is essential: you have a way to look at other points of view, to learn by seeing your own mistakes and to improve your work "). It seems, in fact, that this course promoted an active learning, in opposition to the passive transmission of knowledges and technical training typical of many teachers' learning path in which beginners cannot experience many practice based considerations (Barton \& Haydn, 2006; Harris et al, ibidem; Tondeur, Roblin, van Braak, Voogt \& Prestridge, 2017). However, some were quick to offer critique ("One limitation is the time and having few weekly hours it is difficult to combine the desire to support active learning and that of completing the course programme that has been set"). In terms of learning approaches, $17 \%$ of trainees claimed to have contacted a learning approach they did not know before ("After having known cooperative learning during my TFA, I've applied it several times with my students, and I do appreciate it very much!"). In addition, $22 \%$ reporting that they already had a positive orientation towards a particular methodology but argued that the course had helped to strengthen their knowledge and understanding. 
A small number of trainees (7\%) indicated that that their doubts and difficulties with respect to collaborative learning remained the same despite having actively participated in the course ("Actually, I still do not think this approach can always be applied"). One participant (1\%) was totally against both the methodology (considered as "useless"), and the way it was handled during the course: "Instead of doing all these useless activities, which have not made me learn anything new, because don't you have planned a course on the use of the electronic whiteboard?" (Kat, F, Humanics). These statements once again highlight the role of individual attitudes and opinions respect to the perceived usefulness and efficiency of training programmes (Ertmer, OttenbreitLeftwich \& York, 2006; Ertmer, 2005; Ertmer \& Ottenbreit-Leftwich, 2013; Sadaf, Newby \& Ertmer, 2016).

3.3.2 Change in participants' opinions and attitudes towards technologies in learning

Regarding the use of technologies in school, for $71 \%$ of questionnaire respondents the experience promoted a positive shift in their attitude ("My perspective has changed completely: I understood how the use of technology in education can support the collaborative construction of knowledge and effective social interaction between learners"), with $40 \%$ claiming that the course has also helped them to reflect on possible critical issues (DP4: Transformation and reflection between knowledge and practices) ("I think I have more control of the potentials and weaknesses of the technologies available to $\left.m e^{\prime \prime}\right)$. For four trainees $(6 \%)$ the course has strengthened their already positive conception about the use of technology in education ("My enthusiasm towards ICT tools has been strengthened by a greater awareness"). One trainee though, reported a negative evaluation of his opinions ("I realized that this is a way to hide the 
decline in reading skills and individual concentration and the inability to raise interest in sciences"), and two others showed some scepticism about the use of technology in education ("I am still sceptical, certainly not a passionate advocate of a learning approach merely based on technologies. They are not sufficient to help student grow as learners").

In their reports, however, the trainees dissected the theme of technology and reported how through the course they realized the many opportunities offered for their profession. These opportunities ranged from supporting collaborative activities (50\%), to promoting students' motivation (38\%) and the inclusion of disabled learners (36\%). The technologies are also seen as valuable allies for specific disciplines (31\%), such as arts and languages (DP6: Providing flexible tool mediation). Yet, 27\% of the teachers claimed that, beyond the benefits technology offers, the teacher must remain central: "Our students may be digital natives, but it is important to distinguish - as it has been suggested during the first lesson - between digital dexterity and digital wisdom. The teacher still has a vital role in this sense, for example in stimulating critical thinking and awareness of the potential of technology, pushing students to go beyond their superficial use” (Luc, M; Sciences).

The course indeed proved to be effective in in changing those individual factors - such as the perceived self-efficacy and attitude towards technologies - which are considered as the pre-requisite for a valuable technology application in daily practices (Ertmer, Ottenbreit-Leftwich \& York, 2006).

\section{Conclusions}

The aim of this article was to describe an exploratory study considering a study-specific learning path for trainee teachers based on the "Trialogical" Learning Approach. The 
research sought to verify the capacity of such a learning path to help trainee teachers to learn and understand the potential of technology and collaborative learning. For this result to be achieved, the learners' active participation in the tasks and perceived usefulness of the path is essential. Overall, approximately $95 \%$ of trainee teachers demonstrated some form of active participation in the tasks, with both increased levels of participation and positive perceptions of participation being significantly associated with the assignment of specific roles. Furthermore, a large proportion of trainees reported positive impacts associated with the learning path, including overall course satisfaction, development of knowledge, skills and understanding, and an increase in positive perceptions of both collaborative learning and the use of technologies in a professional context.

The active participation of trainees engaging in the learning path was a positive outcome of the research. The roles attributed to individuals within the working groups were found, in general, to be positive motivators, encouraging not only individual participation but also collaboration with the group. As previously reported in the literature, trainees covering a role tend to participate more than those without a role (Author et al., 2016; Strijbos, Martens, Jochems \& Broers, 2004), perceiving themselves more involved both at a social and a cognitive level (De Wever, Van Keer, Schellens, \& Valke, 2010). Such perceptions were supported for this sample in the results of the trainee questionnaires, in which the majority of trainees who covered a role, reported recognising the effective action of roles in activating their participation. In terms of the "Trialogical" Learning Approach used in this study, which focuses on the collaborative creation of a shared object, the scripted roles used within the study-specific learning path were successful in structuring individual participation within the group.

The learning path delivered to the trainees was generally well accepted. 
According to both the open statements written in the trainee's individual reports and the anonymous responses to the questionnaires, trainees claimed that the course has enriched their expertise with knowledge and skills related to collaborative learning, the use of technology and soft skills related to metacognition and creativity. This acknowledgement was accompanied by their general satisfaction with respect to each activity in the course, with a particular focus on the collaborative building of the pedagogical scenario. Trainees, indeed, claimed to have appreciated the course for its highly experiential emphasis, which allowed them to move from a vision of technology and collaborative learning based on a priori estimates, to one based on direct experimentation, and characterized by critical and informed assessments. Very often, this step resulted in a change of perspective: starting from a negative conception or at least "suspect" view of the use of technology, to a more "constructivist" direction with trainees using technology in the direction advocated by UNESCO (2008), and thus improving their professionalism. To facilitate this change, it is indeed necessary to act both on trainee teachers' knowledge and technological skills and on their attitudes and beliefs towards digital tools (Ertmer, 2005; Ertmer \& Ottenbreit-Leftwich, 2013). To this end, it is essential to provide training programs in which technical training is only the first step to lead then to a higher learning, based on the implementation of concrete activities and projects, as well as problem solving (Park \& Ertmer, 2008). The technology, therefore, should not the primary goal of learning, but is instead the tool that allows trainee teachers to adopt innovative practices (Jonassen, 2006).

The results presented in this study offer a promising insight into the potential effectiveness of collaborative learning paths in providing technology-based pedagogical motivation and support to trainee teachers. However, it is not without its limitations. At present, the research is focussed on the trainee's own perceptions of the success and 
usefulness of the learning path. While this provides a clear insight into the perceptions of the trainees and their willingness to engage in such courses - which, as we saw, are crucial for achieving successful results -, it does not provide a concrete analysis of the learning outcomes achieved on the course. Future research may therefore want to consider reflecting on the knowledge outputs of the learning activity itself (the scenarios produced) to gain a more effective overview of the knowledge, skills and understanding acquired through participation on the course. Furthermore, the present study offers little indication of the long-term impact of engaging in such a learning path. Follow-up investigation of the trainees as they enter their professional careers and actively introduce technologies into their classroom is recommended to appreciate the full potential of adopting a "Trialogical” Learning Approach.

To conclude, the development of a learning path for trainee teachers based on the "Trialogical" Learning Approach has so far demonstrated good potential for increasing the effective use of technologies by trainee teachers. The findings of this study carry practical implications for course providers as they suggest the need for greater opportunities for trainees to develop skills and knowledge via the process of collaboration and role taking to develop not only their motivation and confidence to engage with technology for teaching and learning but also to better prepare them for their professional careers.

\section{References}

Author et al., 2009 [details removed for peer review] Author et al., 2016 [details removed for peer review] Author et al., 2016 [details removed for peer review] Author et al., 2016 [details removed for peer review] Author et al., 2016 [details removed for peer review] 
Banas, J. R., \& York, C. S. (2016). Pre-Service Teachers' Motivation to Use

Technology and the Impact of Authentic Learning Exercises. Exploring the New Era of Technology-Infused Education, 121.

Barton, R., \& Haydn, T. (2006). Trainee teachers' views on what helps them to use information and communication technology effectively in their subject teaching. Journal of computer assisted learning, 22(4), 257-272.

Binkley, M., Erstad, O., Herman, J., Raizen, S., Ripley, M., Miller-Ricci, M., \& Rumble, M. (2012). Defining twenty-first century skills. In Assessment and teaching of 21st century skills (pp. 17-66). Springer Netherlands.

De Wever, B., Van Keer, H., Schellens, T., \& Valcke, M. (2010). Roles as a structuring tool in online discussion groups: The differential impact of different roles on social knowledge construction. Computers in Human Behavior, 26(4), 516-523.

Dillenbourg, P. (2008). Integrating technologies into educational ecosystems. Distance Education, 29(2), 127-140.

Dillenbourg, P., \& Hong, F. (2008). The mechanics of CSCL macro scripts. International Journal of Computer-Supported Collaborative Learning, 3(1), 5-23.

Ertmer, P. A. (2005). Teacher pedagogical beliefs: The final frontier in our quest for technology integration?. Educational technology research and development, 53(4), 2539.

Ertmer, P. A., \& Ottenbreit-Leftwich, A. (2013). Removing obstacles to the pedagogical changes required by Jonassen's vision of authentic technology-enabled learning. Computers \& Education, 64, 175-182. 
Ertmer, P. A., Ottenbreit-Leftwich, A., \& York, C. S. (2006). Exemplary technologyusing teachers: Perceptions of factors influencing success. Journal of Computing in Teacher Education, 23(2), 55-61.

Garrison, D. R., Anderson, T., \& Archer, W. (1999). Critical inquiry in a text-based environment: Computer conferencing in higher education. The internet and higher education, 2(2), 87-105.

Glaser, B. G., \& Strauss, A. L. (2009). The discovery of grounded theory: Strategies for qualitative research: Transaction Publishers.

Guba, E. G., \& Lincoln, Y. S. (1994). Competing paradigms in qualitative research. Handbook of qualitative research, 2(163-194), 105.

Hakkarainen, K., \& Paavola, S. (2009). Toward a trialogical approach to learning. Transformation of knowledge through classroom interaction, 65-80.

Harris, J., Mishra, P., \& Koehler, M. (2009). Teachers' technological pedagogical content knowledge and learning activity types: Curriculum-based technology integration reframed. Journal of Research on Technology in Education, 41(4), 393-416.

Jonassen, D. H. (2006). Modeling with technology: Mindtools for conceptual change. Upper Saddle River, NJ: Pearson Merrill Prentice Hall.

Lawless, K. A., \& Pellegrino, J. W. (2007). Professional development in integrating technology into teaching and learning: Knowns, unknowns, and ways to pursue better questions and answers. Review of educational research, 77(4), 575-614.

Niglas, K. (2000). Combining quantitative and qualitative approaches. Retrieved May, 25th 2016, from http://www.leeds.ac.uk/educol/documents/00001544.htm. 
Paavola, S., \& Hakkarainen, K. (2005). The knowledge creation metaphor-An emergent epistemological approach to learning. Science \& Education, 14(6), 535-557.

Paavola, S., \& Hakkarainen, K. (2014). Trialogical approach for knowledge creation. In Knowledge creation in education (pp. 53-73). Springer Singapore.

Paavola, S., Lakkala, M., Muukkonen, H., Kosonen, K., \& Karlgren, K. (2011). The roles and uses of design principles for developing the trialogical approach on learning. Research in Learning Technology, 19(3), 233-246.

Park, S. H., \& Ertmer, P. A. (2008). Examining barriers in technology- enhanced problem- based learning: Using a performance support systems approach. British Journal of Educational Technology, 39(4), 631-643.

Petrucco, C., \& Grion, V. (2015). An Exploratory Study on Perceptions and Use of Technology by Novice and Future Teachers: More Information and Less On-Line Collaboration?. International Journal of Digital Literacy and Digital Competence (IJDLDC), 6(3), 50-64.

Sadaf, A., Newby, T. J., \& Ertmer, P. A. (2016). An investigation of the factors that influence preservice teachers' intentions and integration of Web 2.0 tools. Educational Technology Research and Development, 64(1), 37-64.

Sfard, A. (1998). On two metaphors for learning and the dangers of choosing just one. Educational researcher, 27(2), 4-13.

Sipilä, K. (2014). Educational use of information and communications technology: teachers' perspective. Technology, Pedagogy and Education, 23(2), 225-241. 
Slavin, R. E. (2010). Co-operative learning: what makes group-work work. The nature of learning: Using research to inspire practice, 161-178.

Strijbos, J. W., Martens, R. L., Jochems, W. M., \& Broers, N. J. (2004). The effect of functional roles on group efficiency: Using multilevel modeling and content analysis to investigate computer-supported collaboration in small groups. Small Group Research, $35(2), 195-229$.

Strijbos, J. W., Martens, R. L., Jochems, W. M., \& Broers, N. J. (2007). The effect of functional roles on perceived group efficiency during computer-supported collaborative learning: a matter of triangulation. Computers in Human Behavior, 23(1), 353-380.

Tondeur, J., Pareja Roblin, N., van Braak, J., Voogt, J., \& Prestridge, S. (2017).

Preparing beginning teachers for technology integration in education: ready for takeoff?. Technology, Pedagogy and Education, 26(2), 157-177.

UNESCO. (2008). ICT Competency Standards for Teachers - Competency Standard Modules. Retrieved July 4, 2017, from http://unesdoc.unesco.org/images/0015/001562/156207e.pdf

Weinberger, A. (2008). CSCL scripts: Effects of social and epistemic scripts on computer-supported collaborative learning. Berlin: VDM Verlag.

Wenger, E., Trayner, B., \& De Laat, M. (2011). Promoting and assessing value creation in communities and networks: A conceptual framework. The Netherlands: Ruud de Moor Centrum, 202010-2011. 